\title{
Neovascularization after surgical exposure of rat external jugular vein endothelium ${ }^{1}$
}

\author{
José Francimário Bezerra do NascimentoI, Guilherme Brandão Benjamin Pitta", Fausto Miranda Junior ${ }^{\mathrm{III}}$
}

IFellow Master degree, Postgraduate Program in Interdisciplinary Surgical Science, Sao Paulo Federal University (UNIFESP), Brazil. Acquisition, analysis and interpretation of data.

IIAssociate Professor, Department of Surgery, State University of Health Sciences of Alagoas, Brazil. Co-advisor, critical revision.

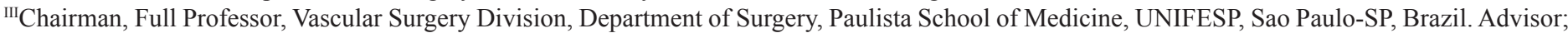
conception, design, intellectual and scientific content of the study.

\section{ABSTRACT}

PURPOSE: To investigate the neovascularization after exposure of the external jugular venous endothelium in an experimental model. METHODS: The sample was composed of 60 male rats of Wistar OUT B breed provided by animal colony of the Medicine College of Juazeiro do Norte, weighing 250 to 350g, aged 90-120 days. Randomized study in OUT B Wistar rats, open, with 60 days duration. The animals were distributed into three groups of 20 specimens and were subjected to the following: Group 1: neck incision with dissection, ligation and section of the external jugular vein. Group 2: neck incision with dissection and ligation of the external jugular vein. Group 3: cervicotomy without dissection of the external jugular vein without ligation or section. The animals were sacrificed, half of them in 30 days and the other half within 60 days. The material in block harvested from the operated site were sectioned and stained for immunohistochemistry with CD34 marker.

RESULTS: Neovascularization occurred with level of significance when compared group 1 to group 3 at 30 days ( $p=0.0076$ ) and the same occurred at 60 days ( $\mathrm{p}=0.0001)$ (Newman-Keuls test).

CONCLUSION: The group with exposure of the venous endothelium showed a significant increase of neovascularization when compared with other groups.

Key words: Neovascularization. Jugular Veins. Endothelium. Rats. 


\section{Introduction}

The process of neovascularization is a key point in a series of physiologic events such as ovulation, wound healing, tumor metastasis dissemination, psoriasis, among others. Thus, the mechanisms involved in the process of neovascularization are critical in seeking to develop mechanisms that inhibit or stimulate, depending on the disease process that is being targeted for treatment.

Varicose veins are common reasons for complaints in clinics and hospitals, and they are characterized as one of the main vascular changes observed in clinical practice, and for this reason they are the focus of numerous studies that attempt to address the causes, incidences and best ways of treatment ${ }^{1,2}$.

Environmental, socioeconomic and hereditary factors, among others, participate to a greater or lesser degree of varicose veins recurrence. Several authors have conducted studies to determine the cause of the recurrence of varicose disease of the lower limbs being the recurrence of varicose veins in the saphenofemoral junction one of the most frequent ${ }^{3-6}$.

It is believed neovascularization by exposure of the venous endothelium during surgery is one of the determining factors of recurrence of varicose veins of the lower limbs, which justifies the study in an experimental model of neovascularization after surgical exposure of the venous endothelium of the external jugular vein in rats.

The aim of this paper was to investigate the neovascularization in an experimental model after the exposure of venous endothelium.

\section{Methods}

Randomized study in experimental animals, open, with 60 days of follow-up performed in the Surgical Technique Laboratory and Experimental Surgery of the Surgical Clinic Division in the Medicine College of Juazeiro do Norte, Ceara. Brazil. This research was submitted to the Ethics Committee of the institution.

The sample was composed of 60 male rats of Wistar OUT B breed provided by animal colony of the Medicine College of Juazeiro do Norte, weighing 250 to 350 g, aged 90-120 days.

The animals were weighed, numbered and subjected to confinement for seven days before the surgical procedure for monitoring and adaptation. The rats were randomized using nontransparent envelopes numbered 1-60, and the first 20 animals randomly selected underwent ligation and section of the external jugular vein and were defined as group 1, from the 21 st to 40 th were defined as group 2 and were subjected to dissection and ligation, no section of the vein, and from the $41^{\text {st }}$ to the $60^{\text {th }}$ animal, defined as group 3, and the procedure was only opening and closing the incision. On the day of surgery, the animals were fasted for four hours and weighed again for surgery. Anesthesia was performed with intraperitoneal phenobarbital sodium at a dose of $30 \mathrm{mg} / \mathrm{Kg}$ to achieve deep sleep.

a) In group 1 we performed a longitudinal neck incision, dissection and isolation of the external jugular vein, which was ligated in its proximal and distal portion with nylon suture 6.0. After a full section was done with scissors aiming the exposition of the venous endothelium. The incision was closed with nylon suture 6.0.

b) The animals of group 2, defined as simulated "sham", underwent the same procedure for opening and dissection of the external jugular vein and its proximal and distal ligation without section of the vein.

c) The animals in group 3 were subjected only to cervical opening and the closing of the incision, group which was defined as "control".

All animals of the three groups at the end of each procedure were referred for daily monitoring in a controlled environment animal facility of the institution.

A new randomized draw was performed selecting half of the animals in which the $30^{\text {Th }}$ and $60^{\text {th }}$ day after surgery, respectively , were euthanized by lethal injection of phenobarbital sodium, and then collected the material in monobloc from the operated region to make hematoxylin-eosin and immunohistochemical exam with marker CD34. In those prepared for immunohistochemistry (CD34-marker) vessels around the external jugular vein were evaluated in an area of 10 high-power fields (x400), and the pathologist had no knowledge of the group to which each case belonged to. The sample size was based on others experimental studies $^{7-9}$. The analysis of variance (ANOVA) was applied and, in this case, the "Newman-Keuls Multiple Comparison Test", by the Statistical Program Graphpad Prism 5.0. The analysis adopted the confidence level of $95 \%$ probability in the comparison of the groups.

\section{Results}

The results for the analysis of 30 days are shown in Figure 1. 


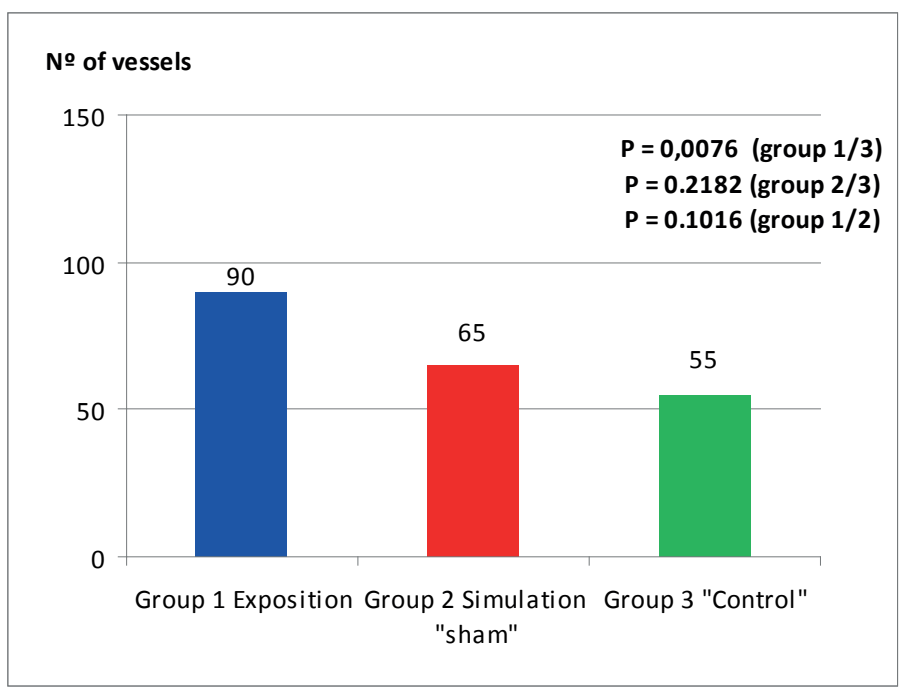

FIGURE 1 - Results after 30 days postoperatively. Comparison between groups (Newman-Keuls Multiple Comparison Test).

The results for the analysis of 60 days are shown in Figure 2.

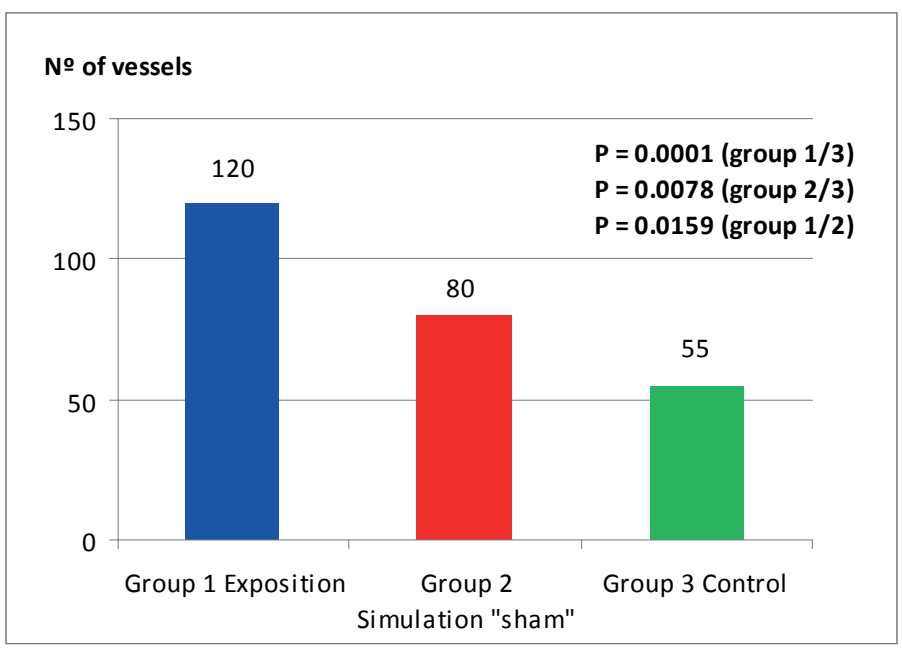

FIGURE 2 - Results after 60 days postoperatively. Comparison between groups (Newman-Keuls Multiple Comparison Test).

The Newman-Keuls test made multiple comparisons among groups considering "p" value of less than 0.05. After 30 days significant difference in average with "p" equal to 0.0076 was obtained between exposition group and the control group. The difference was most evident after the sixty day with $\mathrm{p}=$ 0.0001 . However, we observed a strong significant $\mathrm{p}$ between the simulation group and the control group also.

By way of illustration Figures 3 and 4 show the appearance of histological findings stained with hematoxylineosin and immunohistochemical (CD34) respectively.

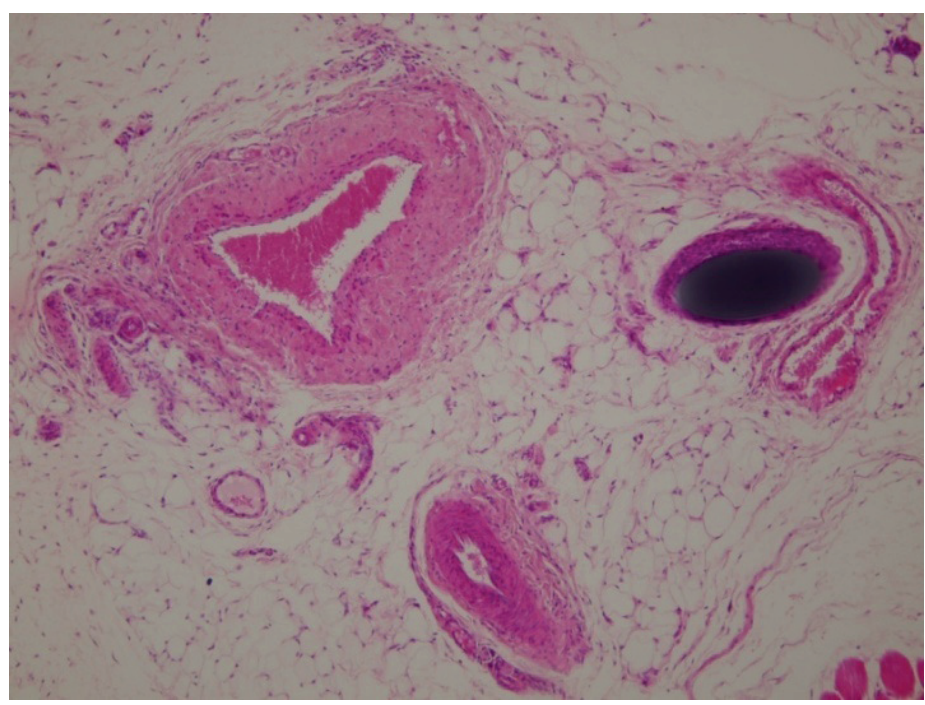

FIGURE 3 - mouse 31 - HE (x100). Area with granulomatous reaction, the kind of foreign body encircling the suture nylon (top right), jugular vein (top left) and carotid artery (bottom center).

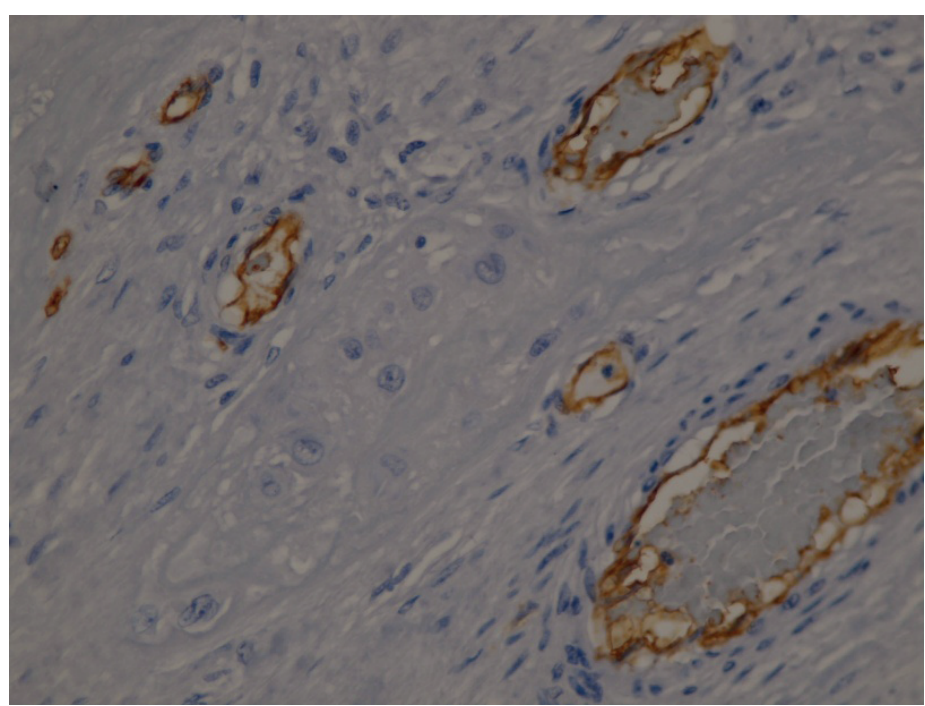

FIGURE 4 - mouse 31. Immunohistochemistry CD 34 (x400). Endothelial cells show brown color (positive for CD 34). Blood vessels of various sizes/gauges are observed, with a predominance of smaller vessels.

\section{Discussion}

It was considered important to include specimens with similar characteristics in order to increase the validity of the results. Randomized selection was made in order to constitute pre-experimental groups with the purpose of reconciling the experiment and the probability. The randomized study serves to separate the groups in the best way to be evidenced clinical observations and findings according to the proposed treatment.

The group undergoing the procedure of sectioning the external jugular vein, exposing the venous endothelium produced more neovascularization when compared with the other groups. 
It was also observed time was factor that contributed to the development of neovascularization, as the 60-day group developed more neovascularization than the 30-day group. Analyzing groups 30 and 60 days clearly demonstrates the presence of angiogenesis in the later observation group. At 60 days a better separation among groups for statistical evaluation were observed suggesting that the surgery itself is also a stimulating factor.

When comparing the average of the study groups after 30 days after surgery, a significant difference of average was obtained when comparing the exposition group to control group only.

However, analyzing the groups after 60 days, the results of comparison between exposition group and simulation group demonstrated a significant difference. These both groups showed a significant difference when compared with the control group These data suggest that both the exposure of the endothelium, as time after the operation and the surgical procedure itself are factors that cause neoangiogenesis.

The result of these experimental superposed clinical reports in the area of Vascular Surgery referring surgical treatment of varicose veins of the lower limbs ${ }^{10-14}$. Patients operated in the 1960s were, 30 years later, underwent ultrasonography of operated area and even with the correct surgical technique, had recurrent varicose veins and neovascularization ${ }^{3,15}$.

This experimental model could be repeated testing drugs or new surgical techniques aimed at reducing the presence of neoangiogenesis.

\section{Conclusions}

The exposure of the venous endothelium in the 30 and 60 day experiment showed a significant increase of neoangiogenesis when compared to the control group. Differences were not identified in groups 2 and 3 in the 30-day period, however to the 60 -day comparison the differences are quite significant suggesting that neoangiogenesis occurs not only by exposure of endothelium and that other variables should be addressed in future studies.

\section{References}

1. De Maesenneer MG, Tielliu IF, Van Schil PE. Clinical relevance of neovascularization on duplex ultrasound in the long term follow up after varicose vein operation. Phebology. 1999;14:118-22.

2. van Rij AM, Jones GT, Hill GB. Neovascularization and recurrent varicose veins: more histologic and ultrasound evidence. J Vasc Surg. 2004;40:296-302.

3. Winterborn RJ, Foy C, Earnshaw J J. Causes of varicose vein recurrence: late results of a randomized controlled trial of stripping the long saphenous vein. J Vasc Surg. 2004;40(4):634-9.

4. Geier B, Mumme A, Hummel T, Marpe B, Stücker M, Asciutto
G. Validity of duplex-ultrasound in identifying the cause of groin recurrence after varicose vein surgery. J Vasc Surg. 2009;49(4):96872.

5. Theivacumar NS, Darwood R, Gough MJ. Neovascularisation and recurrence 2 years after varicose vein treatment for saphenofemoral and great saphenous vein reflux: a comparison of surgery and endovenous laser ablation. Eur J Vasc Endovasc Surg. 2009;38(2):203-7.

6. Luebke T, Gawenda M, Heckenkamp J, Brunkwall J. Meta-analysis of endovenous radiofrequency obliteration of the great saphenous vein in primary varicosis. J Endovasc Ther. 2008;15(2):213-23.

7. Mosquette R, Gomes MPCL, Simões RS, Haidar MA, Simões MJ, Soares Júnior JM, Baracat EC. Efeitos das isoflavonas sobre o miométrio de ratas adultas. Rev Bras Ginecol Obstet. 2006;28(4):227-31.

8. Figueiró Filho EA, Duarte G, Rosa e Silva AAM, Fonseca BAL, Mussi-Pinhata MM, Quintana SM, El Beitune P. Efeito das drogas anti-retrovirais sobre as taxas de fertilidade de ratas Wistar. Rev Bras Ginecol Obstet. 2002;24(10):647-52.

9. Assef JC, Vieira ACPO, Saito HCG, Lancellotte CLP, Szutan LA, De Capua Junior A. Modelo experimental de formação de varizes esofágicas por hipertensão portal esquistossomótica em hamsters. Rev Col Bras Cir. 2005;32(4):209-13.

10. Theivacumar NS, Darwood R, Gough MJ. Neovascularisation and recurrence 2 years after varicose vein treatment for sapheno-femoral and great saphenous vein reflux: a comparison of surgery and endovenous laser ablation. Eur J Vasc Endovasc Surg. 2009;38:2037.

11. Reich-Schupke S, Mumme A, Altmeyer P, Stuecker M. Decorin expression with stump recurrence and neovascularization after varicose vein surgery - a pilot study. Dermatol Surg. 2011;37:480-5.

12. Mouton WG, Marklewitz MM, Friedli S, Zehnder T, Wagner HE, Heim D, De Maeseneer MG. Neovascularisation after surgery for recurrent saphenofemoral incompetence: does surgical dissection technique matter? Vasa. 2011;40:296-301.

13. Schnyder S, Gabler S, Meier TO, Thalhammer C, Magnetti F, Spring S, Amann-Vesti BR. Successful reduction of clinical relevant neovascularization with a modified crossectomy combined with a barrier technique after 10-year follow-up. Phlebology. 2012;27:4048.

14. Brake M, Lim CS, Shepherd AC, Shalhoub J, Davies AH. Pathogenesis and etiology of recurrent varicose veins. J Vasc Surg. 2013;57:860-8.

15. Donati M, Gandolfo L, Brancato G, Privitera A, Donati A. Recurrent varicose veins due to neovascularization: can they be prevented? Chir Ital. 2008;60(1):83-90.

\section{Correspondence:}

Fausto Miranda Junior

Rua Estela, 515/Bl G cj 81

04011-002 São Paulo - SP Brasil

Tel.: (55 11)5572-3839

fmiranda@apm.org.br

Received: Aug 12, 2013

Review: Oct 14, 2013

Accepted: Nov 13, 2013

Conflict of interest: none

Financial source: none

${ }^{1}$ Research performed at Surgical Technique Laboratory and Experimental Surgery, Surgical Clinic Division, Medicine College of Juazeiro do Norte, Ceara. Brazil. Part of Master degree thesis, Postgraduate Program in Interdisciplinary Surgical Science, Sao Paulo Federal University (UNIFESP). Tutor: Fausto Miranda Junior. 